\title{
Diz çevresi osteotomilerinde eksternal fiksatör ile tespit
}

\author{
Osteotomy around knee joint using external fixator
}

\author{
Cengiz Şen \\ İstanbul Üniversitesi, İstanbul Tıp Fakültesi, Ortopedi ve Travmatoloji Anabilim Dalı, İstanbul
}

Diz eklemini oluşturan distal femur ve proksimal tibia kaynaklı deformitelerin tedavisinde, dizin mekaniğinin düzeltilmesi amacı ile eklem koruyucu distal femur osteotomisi (DFO) ve yüksek tibia osteotomisi (YTO) yaygın olarak kullanılmaktadır. Bu hastalarda genellikle deformitenin merkezi ya diz eklemi üzerinde ya da ekleme yakın bir noktada ortaya çıkmaktadır. Deformite analiz edildikten sonra, menteşeler CORA (centre of rotation of angulation) olarak belirlenen noktaya yerleştirilmektedir. Osteotomi sonrası eksternal fiksatörler yardımıyla, hedeflenen deformite miktarı ameliyat sonrasında tedrici olarak düzeltilebilmekte ve mekanik eksen yeniden oluşturulabilmektedir. Osteotomi yapılan hastalarda erken dönemde ağrı geçmekte, fonksiyonel aktivite artmakta olup; uzun dönemde ise etkilenen eklem aralığındaki birim kıkırdak yüzeye gelen yüklerin azalması sonucu, uzun bir sağkalım sağlanmakta ve total diz protezine geçiş ortalama 10 yıl ertelenebilmektedir. Bu sürenin sonunda, total diz artroplastisine dönüş düşük komplikasyon oranıyla güvenle uygulanabilmektedir.

Anahtar sözcükler: deformite; distal femur; proksimal tibia; osteotomi; eksternal fiksatör
Joint-preserving distal femoral osteotomies (DFO) and proximal tibial osteotomies (HTO) are frequently used to correct the mechanics of the knee in deformities resulting from distal femur and proximal tibia, which constitute the knee joint. In these patients, the center of the deformity is usually located in the knee joint or close to it. Following deformity analysis, the hinges are placed at the point determined as CORA. After osteotomy, the targeted correction of the deformity can be gradually achieved postoperatively with the use of external fixators and the mechanical axis can be reconstituted. In patients who have undergone osteotomy, pain decreases in the short term and functional activities improve while in the long term due to the decrease in loads effect on the unit cartilage surfaces in the joint space, a long survival time is achieved and conversion to total knee arthroplasty can be postponed for an average of 10 years. After this period, conversion to total knee arthroplasty can be safely done with low complication rates.

Key words: deformity; distal femur; proximal tibia; osteotomy; external fixator
D eformite, normal anatomiden sapma olarak tanımlanmaktadır. Bu sapma, uzunluk, rotasyon, angulasyon veya translasyon şeklinde olabilir. Deformite analizinin amacı, bu sapma ya da sapmaların yönünün ve miktarının tanımlanması ve tedaviye yol göstermesidir. Deformite planlaması, hastanın öykü ve fizik muayenesi ile başlar. Tedavide yol gösterici tek etken ölçülen normal dışı değerler değildir. Deformitenin arkasındaki patogenez ve hasta beklentileri de aynı derecede öneme sahiptir.

Deformite analizinde iki önemli kavram bulunur: Dizilim ve yönelim. Dizilim (alignment), kalça, diz ve ayak bileğinin frontal plandaki eksenini tanımlar.
Yönelim (orientation) ise eklem yüzeyinin, ilgili kemiğin anatomik veya mekanik ekseni ile olan ilişkisini ifade eder. Bu ilişkiyi tanımlamak için mekanik ve anatomik kemik eksenleri kullanılır. Mekanik eksen, bir uzun kemiğin, proksimal ve distal eklemlerinin orta noktalarını birleştiren çizgidir. Anatomik eksen ise kemik diyafizinin orta noktalarının birleştirilmesi ile oluşan, uzun aksını ifade eden çizgidir. Kalça, diz ve ayak bileği eklemlerinin uzunlamasına yerleşimlerinin fizyolojik durumda olmaması "kötü dizilim" (malalignment) olarak tanımlanır. Bir uzun kemiğin eklem yüzeyinin aynı kemiğin anatomik eksenine göre fizyolojik konumunun bozulması ise "kötü yönelim" (maloryantasyon) olarak tanımlanır. ${ }^{[1-3]}$

- Illetişim adresi: Prof. Dr. Cengiz Şen, İstanbul Üniversitesi, İstanbul Tıp Fakültesi, Ortopedi ve Travmatoloji Anabilim Dalı, İstanbul Tel: 0532 - 2456365 e-posta: senc64@gmail.com

- Geliș tarihi: 20 Ocak 2020 Kabul tarihi: 19 Șubat 2020 
Normal anatomiden sapmanın analiz edilebilmesi için, normal değerlerin bilinmesi gereklidir. Alt ekstremitenin normal değerleri birçok çalışmanın ürünü olarak ortaya çıkmıştır. Bu değerler çeşitli araştırıcılar tarafından deformite analizi olarak derlenmiş ve farklı tanımlamalar kullanılarak yayınlanmıştır. ${ }^{[1-3]}$ Bu durum literatürde çelişkili verilerin ortaya çıkmasına, yöntem ve ifade karmaşasına yol açmıştır. Bu nedenle Paley tarafindan bugün kullandığımı isimlendirmeler ve yöntem ortaya konarak deformite analizi standardize edilmiştir. ${ }^{[4]}$

\section{MUAYENE}

\section{Klinik Muayene}

Deformite analizi yapılacak hasta ilk olarak klinik muayene ile değerlendirilmelidir. Hasta önce üzerindeki giysileri çıkarılarak yürütülmeli, bu esnada destek kullanıp kullanmadığı, aksama bulunup bulunmadığı ve lomber bölge patolojilerinin olup olmadığı dikkate alınmalıdır. Daha sonra Trendelenburg testi yapılmalıdır. Ardından hastada eklem kontraktürlerinin olup olmadığı, kısalık bulunup bulunmadığı, eklem hareket açıklığı ve kas güçleri tam olarak değerlendirilmelidir. Son olarak da hasta ekstremite ve ekleme yönelik olarak özel testler varsa, onlar da yapılarak klinik muayene tamamlanmalıdır.

\section{Radyolojik Muayene}

Deformite analizinde günümüzde en sık kullanılan yöntem "ortoröntgenogram"dır. İlk olarak Green ve ark. tarafından 1947'de tanımlanmıştır. ${ }^{[5]}$ Kaset, ayakta durmakta olan ve patellaları öne bakan hastanın arkasına yerleştirilir. Kalça, diz ve ayak bileklerini merkez alarak yapılan üç ayrı çekim ile görüntü elde edilir ve birleştirilir. Günümüzde hem çekim hem de birleştirmeler dijital olarak yapılmaktadır (Şekil 1).

Bu çekimlerde cihazların uzaklık kalibrasyonu yapılsa da, boyutları bilinen radyo-opak araçların da (metal top, çubuk vs.) ekstremite ile aynı planda görüntüye dâhil edilmesi ölçeklendirme için önemlidir. Aynı zamanda kısa olan ekstremitelerin, pelvik paralellik sağlanana kadar yükseltilmesi gerekir. Günümüzde normal radyografiden on kat daha düşük dozlarda radyasyon ile çalışan ve vücut taramalarında kullanılan düz radyografi cihazları mevcuttur. Alt ekstremitedeki sagittal plan süperpozisyonu bu cihazların zayıf yönüdür. Cihazın pahalı ve yeni teknoloji olması sebebi ile ulaşılabilirliği güçtür.

\section{DEFORMITE ANALIZi}

\section{Kemik Eksenleri Çizimi}

Frontal plan analizi için alt ekstremitenin mekanik ekseni çizilir. Femur başı orta noktasından, ayak
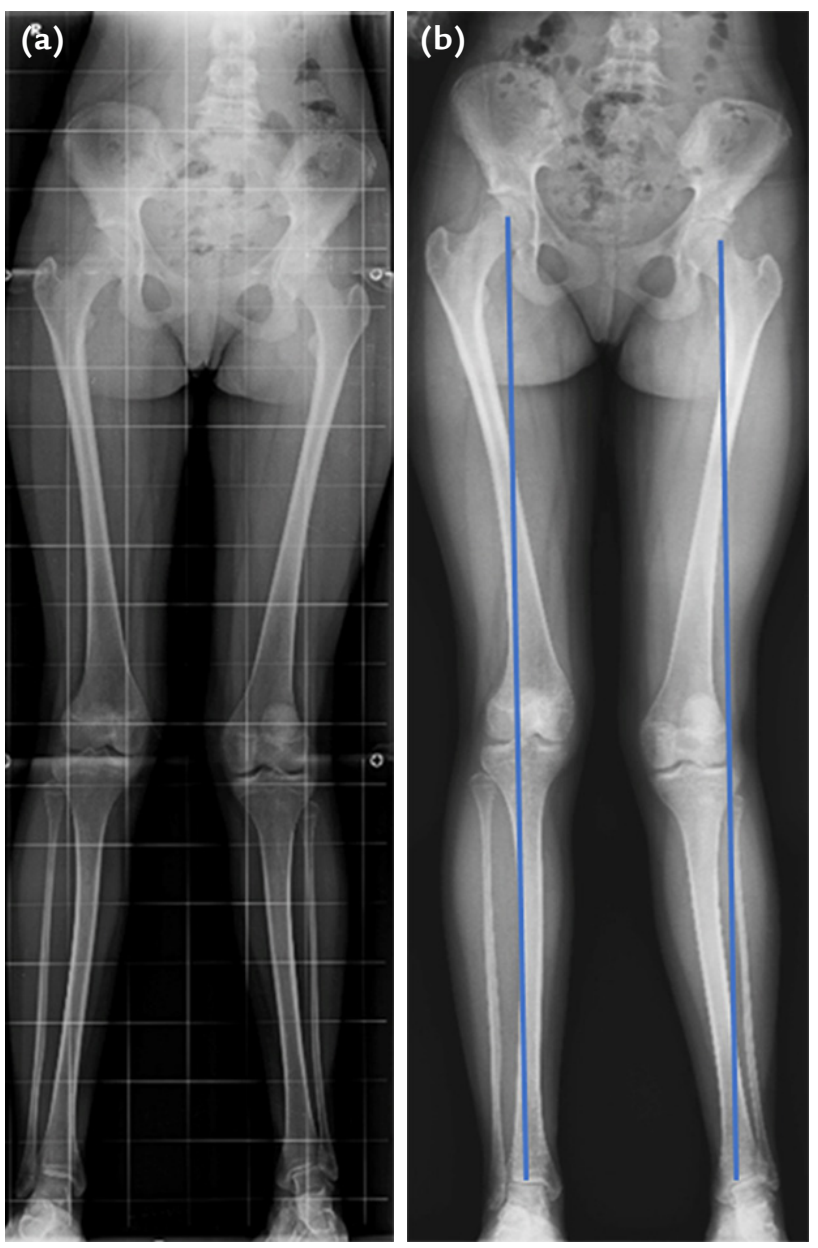

Şekil 1. a, b. Deformite analizinde günümüzde en sık kullanılan radyolojik yöntem olan ortoröntgenogram. Aynı hastanın analog (a) ve dijital olarak (b) çekilerek birleştirilmiş bir yıl ara ile büyüme takibi esnasındaki ortoröntgenogramı görülmektedir. Bu ortoröntgenogramda mekanik eksenin çizilmesi (mavi çizgi).

bileği eklemi orta noktasına kadar çizilen düz doğru, alt ekstremite mekanik eksenidir. Bu eksende normal değerlerden sapma "Mekanik Eksen Sapması" (MAD) olarak tanımlanır. Bu duruma sebep olan deformitenin kaynağı için femur ve tibia ayrı ayrı analiz edilmelidir. Femurun mekanik eksenini çizmek için femurun proksimal ve distal eklem merkezleri bulunur. Bu merkezler bir doğru ile birleştirilerek femurun mekanik ekseni çizilmiş olur. Femurun anatomik ekseni için ise diyafizer orta noktaların birleştirilmesi yeterlidir. Anatomik eksen diyafizin orta noktalarını birleştiren çizgi olduğu için mekanik eksen gibi doğrusal olmayabilir. Frontal planda femurun anatomik ve mekanik eksenleri arasında ortalama $7^{\circ} \pm 2^{\circ}$ açı vardır. ${ }^{[6]}$ 


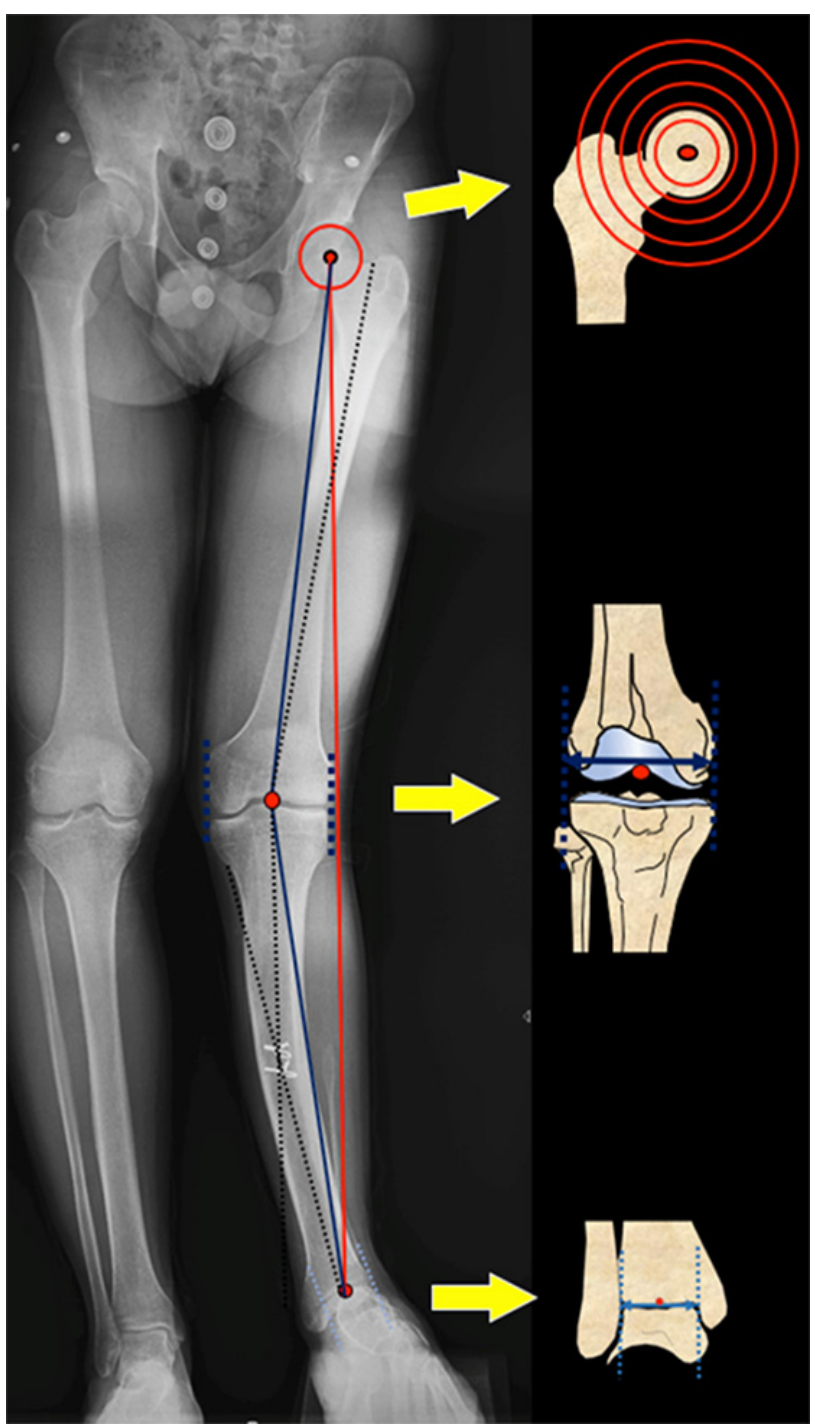

Şekil 2. Alt ekstremite mekanik ekseninin (kırmızı çizgi), eklem yüzeyi orta noktalara göre çizilmesi ve fibular hemimeli hastasında lateral eksen sapmasının gösterilmesi. MAD tespitinin ardından femur ve tibianın mekanik (düz siyah çizgi) ve anatomik (kesikli siyah çizgi) eksenlerinin ayrı ayrı çizilmesi. Tibiada distal ve proksimal diyafizin birbirleri ile kesişen anatomik eksenleri olduğuna dikkat ediniz.

Tibia mekanik eksenini çizmek için proksimal ve distal eklem orta noktalarının tespit edilmesi gereklidir. Bu noktalar birleştirilir ve tibianın mekanik ekseni çizilir. Anatomik eksen için ise diyafize dikey olarak çizilen çizgilerin orta noktaları bulunur ve birleştirilir. Frontal planda tibianın anatomik ve mekanik eksenleri birbirine paraleldir ve aralarında sadece birkaç $\mathrm{mm}$ aralık vardır. Bu nedenle pratikte anatomik ve mekanik eksen aynı kabul edilir (Şekil 2). ${ }^{[6]}$

\section{Eklem Oryantasyon Çizgilerinin Belirlenmesi}

Frontal planda proksimal femur eklem oryantasyon çizgisinin belirlenmesi için iki çizgiden yararlanılır. Büyük trokanter tepe noktasını femur başı merkezi ile birleştiren çizgi ve femur boynu orta noktasını femur başı merkezi ile birleştiren çizgi. Distal femurun eklem oryantasyon çizgisi femur kondilinin en distal noktalarının medial ve lateralde birleştirilmesi ile oluşturulur. Düz grafide gördüğümüz en distal nokta subkondral kemiktir. Frontal planda tibia proksimal eklem oryantasyon çizgisini çizmek için, iki tibial platonun subkondral çizgisinin konkav noktaları birleştirilir. Frontal planda tibia distal eklem oryantasyon çizgisini çizmek için, distal tibianın subkondral çizgisi esas alınır (Şekil 3).

\section{Deformite Açıları}

Femur başı merkezi ile trokanter tepesini birleştiren çizgi, femur mekanik ekseni ile lateralde ortalama $90^{\circ}$ (en az $85^{\circ}$, en çok $95^{\circ}$ ) açı yapar. Bu açıya "mekanik eksene göre lateral proksimal femoral açı" (mLPFA) (Şekil 4) adı verilir. Femur başı merkezi ile trokanter tepesini birleştiren bu çizgi anatomik eksenle medialde ortalama $84^{\circ}$ (en az $80^{\circ}$, en çok $89^{\circ}$ ) açı yapar. Bu açıya "anatomik eksene göre medial proksimal femoral açı" (aMPFA) adı verilir. Femur başı merkezini femur boynu orta noktası ile birleştiren çizgi anatomik eksenle medialde ortalama $130^{\circ}$ (en az $124^{\circ}$, en çok $136^{\circ}$ ) açı yapar. Bu açıya "anatomik eksene göre medial baş boyun açısı" (aMNSA) adı verilir. Distal femur eklem oryantasyon çizgisi femur mekanik ekseni ile lateralde ortalama $87^{\circ}$ (en az $85^{\circ}$, en çok $90^{\circ}$ ) açı yapar. Bu açıya "mekanik eksene göre lateral distal femoral açı" (mLDFA) adı verilir. Bu çizgi anatomik eksenle lateralde ortalama $81^{\circ}$ (en az $79^{\circ}$, en çok $83^{\circ}$ ) açı yapar. Bu açıya "anatomik eksene göre lateral distal femoral açı" (aLDFA) adı verilir (Şekil 4). ${ }^{6]}$

Proksimal tibia eklem oryantasyon çizgisi tibia mekanik ekseni ile medialde ortalama $87^{\circ}$ (en az $85^{\circ}$, en çok $90^{\circ}$ ) açı yapar. Bu açıya "mekanik eksene göre medial proksimal tibial açı" (mMPTA) adı verilir. Bu çizgi anatomik eksenle medialde aynı derece açı yapar. Çünkü tibianın anatomik ve mekanik ekseni aynı kabul edilir. Distal tibia eklem oryantasyon çizgisi tibia anatomik ve mekanik ekseni ile lateralde ortalama $89^{\circ}$ (en az $86^{\circ}$, en çok $92^{\circ}$ ) açı yapar. Bu açıya "mekanik eksene göre lateral distal tibial açı" (mLDTA) adı verilir (Şekil 4). ${ }^{[7]}$

\section{Frontal Plan Kötü Dizilim Testi}

Alt ekstremitede deformite olduğu düşünülen bir hastada ilk yapılması gereken; bu ekstremitede bir 


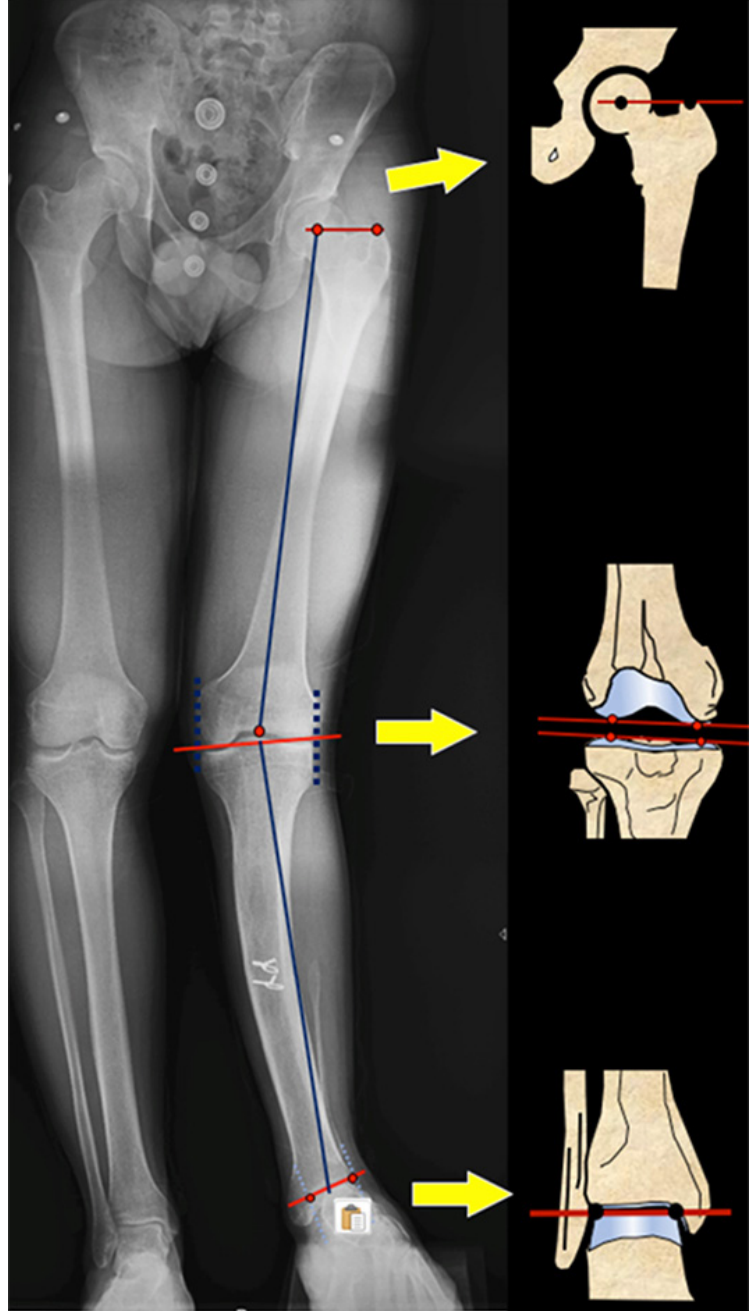

Şekil 3. Frontal planda femurun distal ve proksimali ile tibianın distal ve proksimal eklem oryantasyon çizgilerinin çizilmesi.

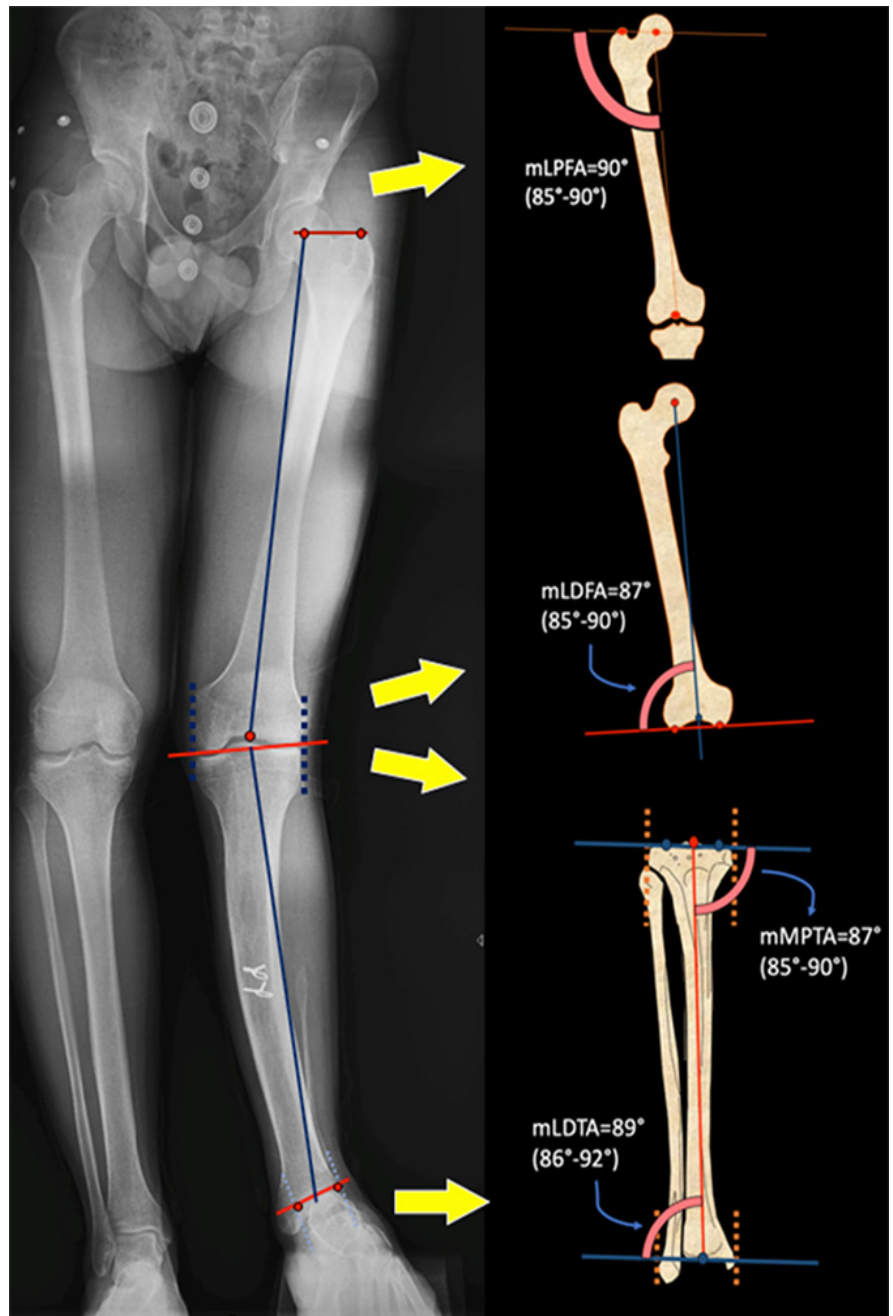

Şekil 4. Alt ekstremite eklem oryantasyon açılarının çizilmesi. Tüm deformite açılarının mekanik eksen referanslı belirlendiğine dikkat ediniz. Aynı açıların anatomik eksen referansları da bulunmaktadır. deformitenin olup olmadığını saptamak, deformite varsa deformitenin hangi kemikten kaynaklandığını bulmak ve son olarak da deformitenin merkezini (CORA) bulmaktır. Illk iş olarak, alt ekstremite mekanik ekseni çizilerek "kötü dizilim testi", (malalignment test, MAT) rutin olarak yapılır. Böylelikle "Deformite var mı? Yok mu?" sorusunun cevabı alınır.

Kötü Dizilim Testi 0 (Deformite Var mı?): Alt ekstremite mekanik ekseni, dizin merkezinin ortalama $8 \pm 7 \mathrm{~mm}$ medialinden geçer. Sınırların dışında medializasyon "varus" deformitesini, lateralizasyon ise valgus deformitesini tanımlar.

Kötü Dizilim Testi 1 (Deformite Nerede? Femurda mı?): Femur mekanik ekseni ile proksimal ve distal eklem oryantasyon çizgileri çizilir. LDFA normalde $87^{\circ}$ dir. Bu açı $90^{\circ}$ 'den büyükse varus, $85^{\circ}$ 'den küçükse valgus deformitesini tanımlar (Şekil 5).

Kötü Dizilim Testi 2 (Deformite Nerede? Tibiada mı?): Tibia mekanik ekseni ile proksimal ve distal eklem oryantasyon çizgileri çizilir. Oluşan MPTA açısı, normalde $87^{\circ}$ 'dir. Bu açı $90^{\circ}$ 'den büyükse valgus, $85^{\circ}$ 'den küçükse varus deformitesini tanımlar.

Kötü Dizilim Testi 3 (Deformite Nerede? Diz Ekleminde mi?) Distal femur ve proksimal tibia eklem oryantasyon çizgileri arasındaki JLCA (eklem uyum çizgisi-joint line convergence angle) ölçülür. Normalde paralel olan bu çizgiler arasında $2^{\circ}$ 'ye kadar açı farkı olabilir. Daha fazla açı olması deformitenin diz ekleminde olduğunu gösterir. Açılanma medialde ise valgus, lateralde ise varus deformitesini tanımlar. 


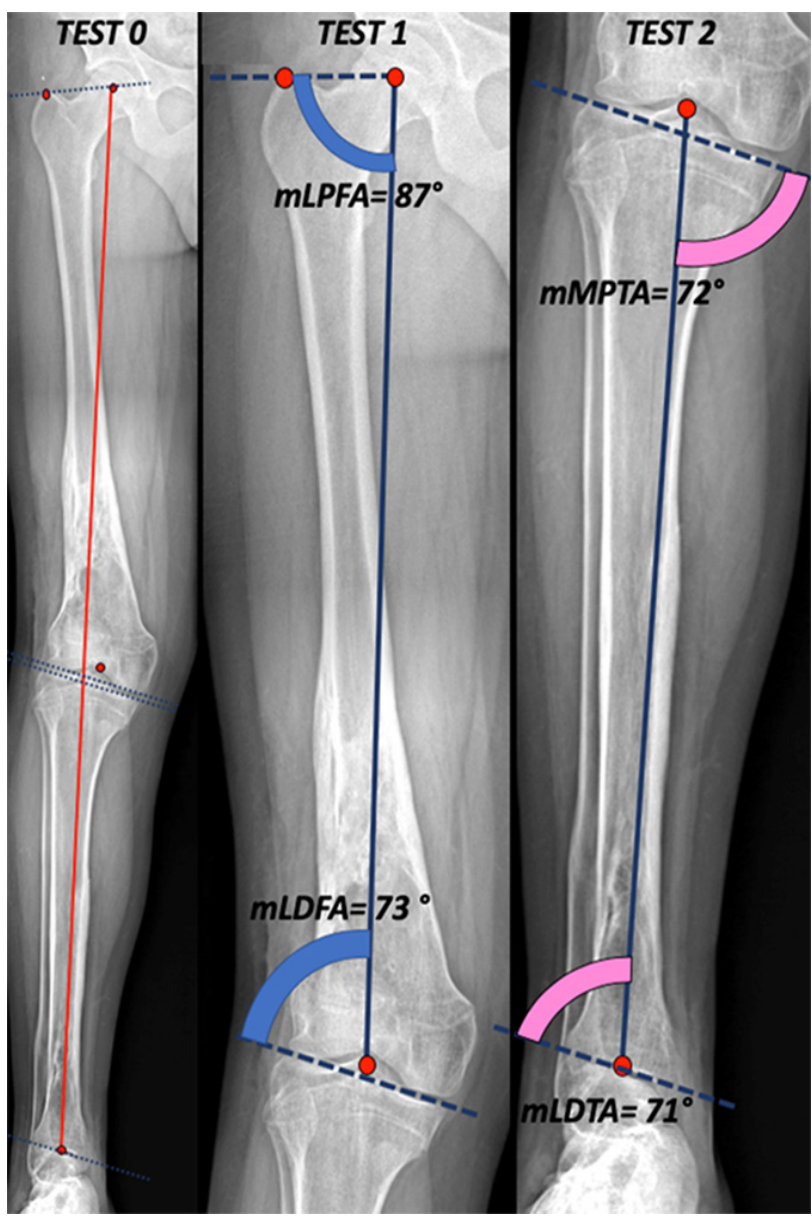

Şekil 5. Post travmatik, distal femur valgus ve proksimal tibia varus deformitesi ve kısalık bulunan olgunun kötü dizilim testi basamakları ile incelenmesi. Test 0'da lateralize mekanik eksenin tespit edilmesi, Test 1'de femur mekanik eksenindeki distal sapma, Test 2'deki tibia proksimal ve distalinde maloryantasyon tespit edilmesi.

Ilave 1: Diz Ekleminde Subluksasyon Var mı? Distal femur ve proksimal tibia eklem oryantasyon çizgileri çizilir ve bunların orta noktaları alınarak birbiri ile kıyaslanır. Bu iki nokta aynı hizada bulunur. Aralarındaki mesafe 3 mm'ye kadar normal kabul edilir; 3 mm'den fazla mesafe varsa alt ekstremite kötü diziliminin sebebi diz subluksasyonudur.

ilave 2: Kondil ya da Plato Dizilim Bozukluğu Var mı? Her iki femoral kondil ve tibial platonun eklem yüzeyleri ayrı ayrı çizilir. Tibial platonun eklem yüzey çizgileri birbirini takip eder, aralarında açı veya merdivenleşme yoktur. Bu paralellik bozulmuşsa veya merdivenleşme oluşmuşsa platoda kötü dizilim söz konusudur. Aynı şey femoral kondiller için de geçerlidir. Bu durum eklem içi deformitelere örnek olarak gösterilir. ${ }^{[6]}$

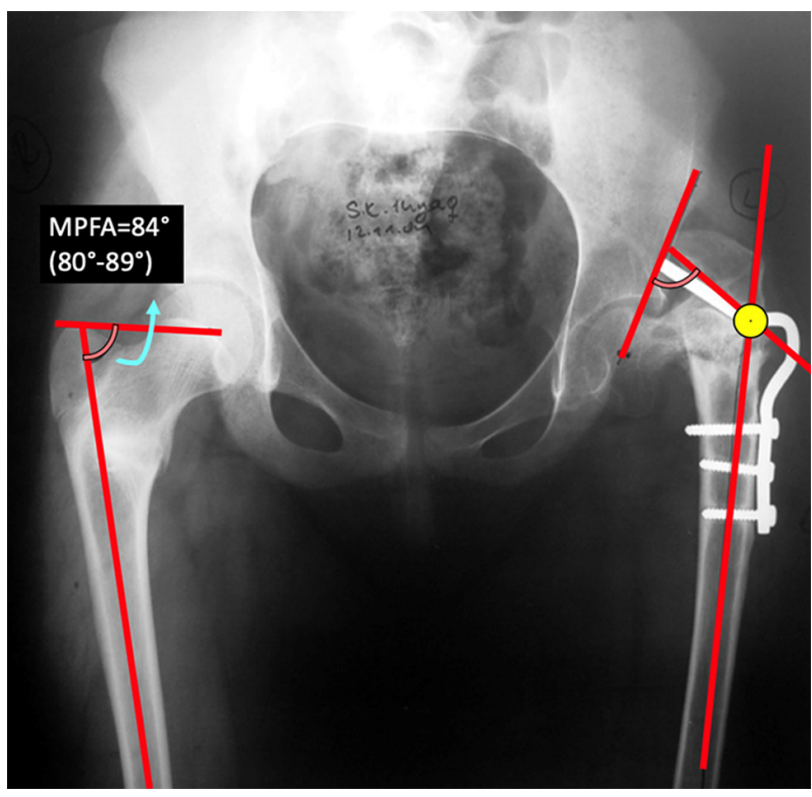

Şekil 6. Proksimal femurda MOT-1 ve MOT-2'nin uygulanması. MOT-1'de anatomik eksenler arasındaki ilişki, MOT-2'de ise mekanik eksenler arasındaki ilişki görülmektedir.

\section{Frontal Plan Kötü Yönelim Testi}

Diz ekleminde eklem yüzeylerinde kötü yönelim olduğu zaman aynı zamanda kötü dizilim de ortaya çıkar. Bu durum kötü yönelim testi (MOT) ile kolayca belirlenir. Bu nedenle MOT diz ekleminde mekanik eksen sapması ile birlikte hatalı oryantasyonu da ortaya çıkarır. Kalça ve ayak bileğinde durum farklıdır. Tibia distal uçta ve femur proksimal kısımda kalça ve ayak bilek merkezlerine yakın yerde deformite olduğu zaman, dizilim kusuru genellikle görülmez veya minimaldir. Bu nedenle kalça ve ayak bileğine yakın yerlerde oluşan deformite MAT ile ortaya konamaz. Deformite analizinin tam olmasını istiyorsak MAT yaptıktan sonra kalça ve ayak bileği MOT'u yapmalıyız.

Bunun için proksimal femur eklem oryantasyon çizgisi çizilir ve mLPFA ölçülür. Bu teste MOT-1 denir ve mekanik eksenler arası ilişkiyi gösterir. MOT-2'de ise anatomik eksenler arası ilişki tespit edilir. Femur başı merkezini, femur boynunun orta noktası ile birleştiren çizgi, yani baş-boyun çizgisi çizilir. Bu çizginin femur anatomik ekseni ile ilişkisi araştırılır. Medialde oluşan aMPFA ölçülür. Normalde $84^{\circ}$ (en az $80^{\circ}$, en çok $89^{\circ}$ ) olması gereklidir (Şekil 6). Tibia distal eklem yüzünde hatalı oryantasyon olup olmadığını anlamak için lateral distal tibial açı çizilir ve ölçülür. LDTA'yı çizmek için önce distal tibia eklem oryantasyon çizgisi çizilir. Sonra distal tibianın anatomik ekseni veya mekanik ekseni çizilir. Lateralde oluşan LDTA ölçülür. Bu açı normalde 


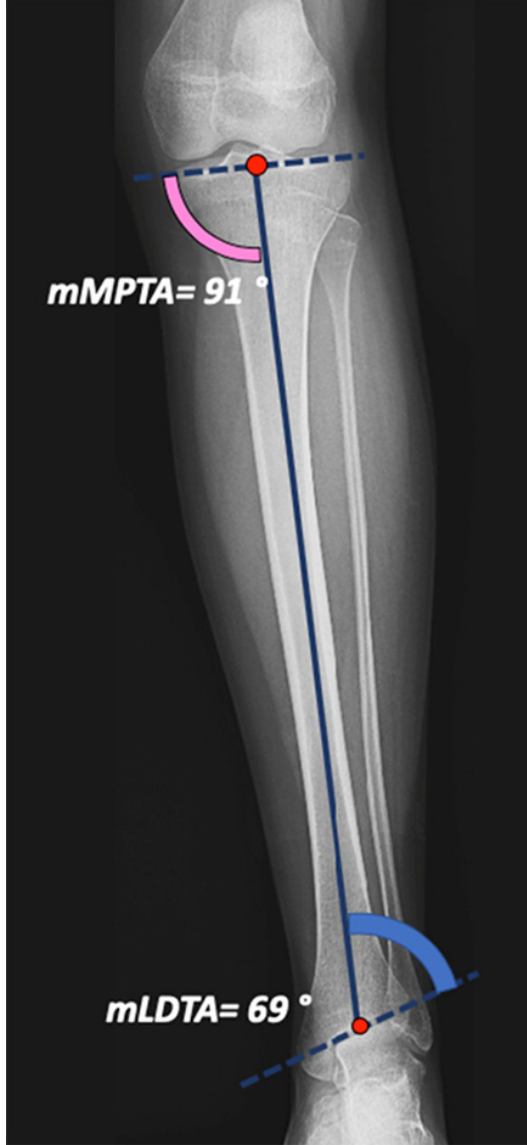

Şekil 7. Distal tibia maloryantasyonun tespit edilmesi için MOT-3'ün uygulanması. Ayak bileğindeki valgus deformitesine dikkat ediniz.

$89^{\circ}$ (en az $86^{\circ}$ en fazla $92^{\circ}$ ) olmalıdır. Bu test ise MOT-3 olarak adlandırılır (Şekil 7). ${ }^{[6]}$

\section{Deformitenin Merkezi (CORA)'nin Bulunması ve Osteotomi Yerinin Saptanması}

Dizilim ve yönelim testleriyle deformitenin olup olmadığı, varsa hangi kemikten (femur, tibia) kaynaklandığı ve kemiğin hangi bölgesinden meydana geldiği saptandıktan sonra deformitenin merkezi, yani CORA bulunmalıdır. Çünkü gerek sirküler gerekse monolateral fiksatörle yapılacak düzeltmelerde menteşe ekseni düzeltme ekseninde yerleştirilmeli, bu mümkün değilse menteşe ekseni farklı bir yere yerleştirildiğinde oluşacak translasyon dikkate alınmalıdır. ${ }^{[6-8]}$

Gerek femur gerek tibiada CORA'yı bulmak için anatomik veya mekanik eksenlerden yararlanilır. Ancak femurda mekanik eksenle deformite analizi ve
CORA'nın bulunması daha zor olduğundan, günlük pratikte anatomik eksen daha fazla tercih edilmektedir. Tibiada ise, $2 \mathrm{~mm}$ translasyon farkı olmasına rağmen anatomik ve mekanik eksenler eşit kabul edildiğinden, deformite analizi mekanik eksen üzerinden yapılmalıdır. Ancak hiç unutulmaması gereken özellik; hangi ekseni kullanıyorsak o eksene ait yönelim açıları dikkate alınmalıdır. ${ }^{[8]}$ (mLDFA, mMPTA, aLDFA, aMPTA vb) (Şekil 8).

Femurda anatomik ve tibiada mekanik eksenler üzerinden planlama yapacağımızı varsayarak; önce mekanik eksen sapması belirlenmeli, daha sonra anatomik ve mekanik yönelim açıları bulunmalıdır (femur için: aLDFA, aMPFA; tibia için: mMPTA, mLDTA). Bu yönelim açılarına göre deformitenin proksimal ve distal eksenleri çizilmelidir. Daha sonra her iki eksenin kesişme noktası bize deformitenin merkezi olan CORA'yı ve açısal olarak da deformitenin büyüklügüüü verecektir (Şekil 9). ${ }^{[8]}$

CORA bulunduktan sonra, sıra osteotominin yapılmasına gelir. Dror Paley tarafından tarif edilen üç temel osteotomi kuralı vardır. ${ }^{[9,10]}$ Osteotomi sonrası düzeltme açıcı kama, kapayıcı kama veya nötral şekilde yapılabilir. Hastada açılanmayla beraber kısalık varsa, açıcı kama osteotomi; uzunluk varsa kapayıcı kama; ekstremite eşitsizliği yoksa nötral tipte düzeltme yapılmalıdır. Paley'nin ortaya koyduğu diğer bir önemli özellik de menteşe ekseninin yerleştirilme yeridir. Menteşe ekseni ve osteotomi yeri CORA ile aynı seviyede ise sadece açılanma düzeltilir (osteotomi kural 1). Menteşe ekseni CORA ile aynı seviyede, ancak osteotomi farklı 

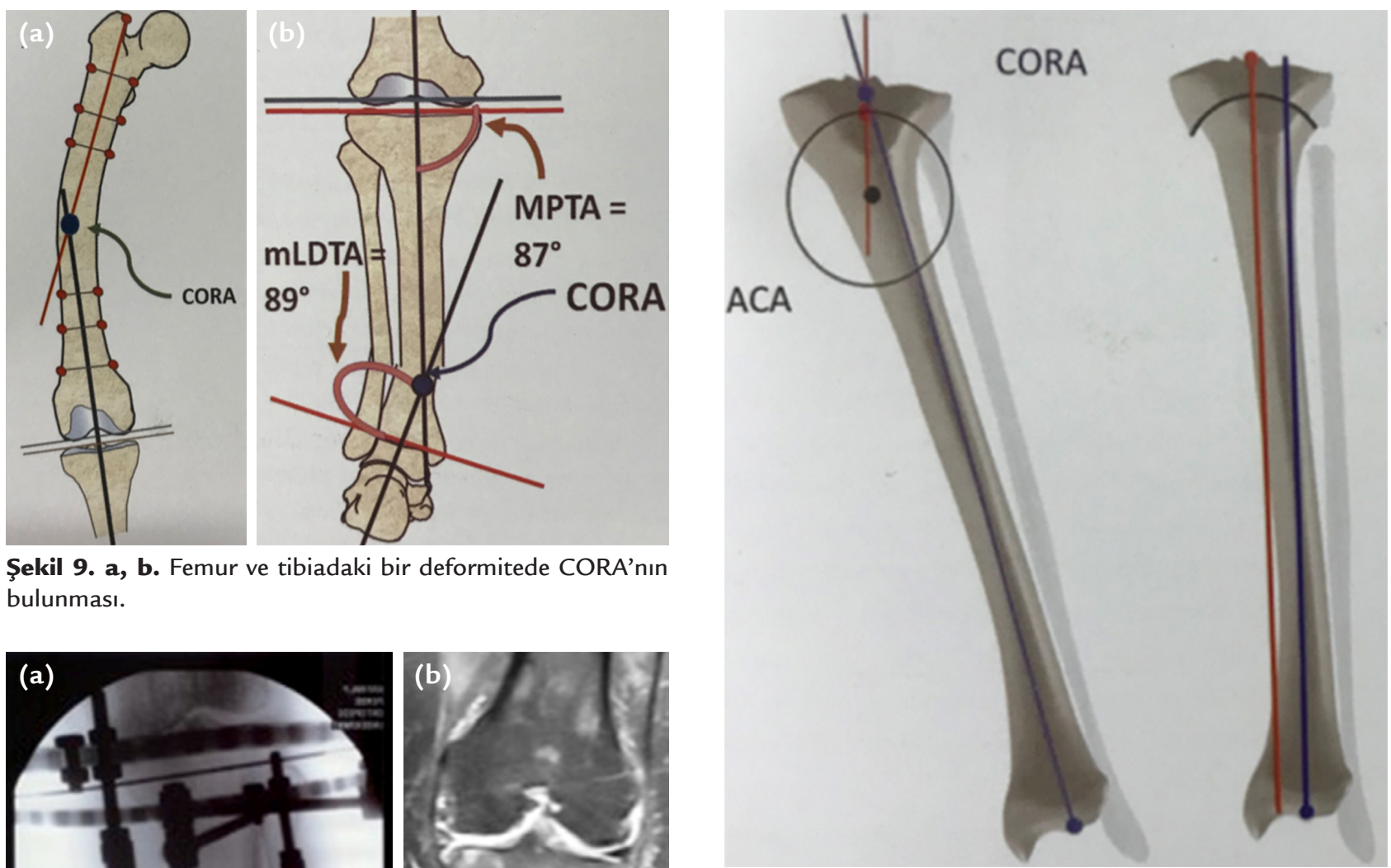

Şekil 9. a, b. Femur ve tibiadaki bir deformitede CORA'nın bulunması.
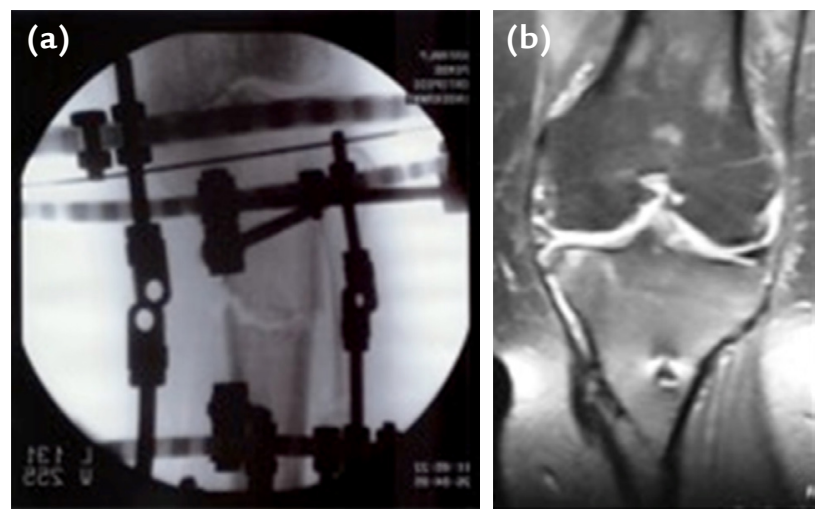

Şekil 10. a, b. Medial açık kubbe-dome ostetomisinde medial uzantı, medial kollateral bağın (MCL) yapışma yerinin üzerinde sonlanmaktadır.

bir seviyeden yapılmışsa açılanma düzelirken translasyon meydana gelir. Ancak bu translasyon istenen bir durumdur (osteotomi kural 2). Proksimal tibiadaki kubbe osteotomisi buna en güzel örnektir (Şekil 10).

Şekil 11. Maquet tarzı bir osteotomi yapıldığında, Osteotomi kural 3 meydana gelir. Bunun sonucunda Zig-Zag deformitesi dediğimiz istenmeyen bir kozmetik görünüm olur.

Osteotomi kural 3 ise, olmasını çok istemediğimiz bir düzeltmeyi açıklar. Burada düzeltme ekseni (ACA), osteotomi ve menteşe ekseni farklı bir yerde konumlanmıştır. Düzeltme sonunda proksimal ve distal eksenler arasında translasyon olur ki, zig-zag deformitesi olarak özellikle tibiada istenmeyen bir kozmetik görüntü meydana gelir (Şekil 11).

Bütün bu osteotomi kuralları Tablo 1'de gösterilmiştir.

Tablo 1. Dror Paley tarafindan tarif edilen osteotomi kuralları ${ }^{[9,10]}$

\begin{tabular}{lccc}
\hline & CORA & ACA & Osteotomi \\
\hline Kural 1 & Aynı & Aynı & Aynı \\
Kural 2 & Aynı & Aynı & Farklı \\
Kural 3 & Farklı & Farklı & \\
\hline
\end{tabular}

CORA, deformite merkezi; ACA, düzeltme ekseni. 
Tablo 2. Dror Paley’in eklem çevresi bağ laksitesi varlığındaki tedavi önerileri ${ }^{[11]}$

\begin{tabular}{lllll}
\hline LDFA & MPTA & JLCA & S-JLCA & Önerilen osteotomi \\
\hline $85-90$ & $\leq 85$ & $\geq 0$ & $>$ JLCA + 3 & TO + LT \\
$85-90$ & $85-90$ & $>0$ & $>$ JLCA +3 & TO + LT \\
$\geq 92$ & $85-90$ & $\geq 0$ & $>$ JLCA +3 & FO \pm LT \\
$90-92$ & $87-90$ & $\geq 0$ & $>$ JLCA +3 & FO \pm LT \\
$90-92$ & $\leq 86$ & $\geq 0$ & $>$ JLCA +3 & TO + LT \\
$\geq 92$ & $<85$ & $\geq 0$ & $>$ JLCA +3 & FO + TO + LT \\
\hline
\end{tabular}

LDFA, lateral distal femoral açı; MPTA, medial proksimal tibial açı; JLCA, eklem uyum çizgisi; S-JLCA, stres grafisindeki eklem uyum çizgisi; TO, tibial osteotomi; FO, femoral osteotomi; LT, ligament sıkılaştırma.

Tüm bu deformite analizi prensipleri uygulanarak bulunan femur veya tibia kaynaklı deformite vakalarında uygun bir osteotomi yapıldıktan sonra deformiteyi düzeltmek için; sirküler fiksatör, monolateral fiksatör veya bilgisayar destekli uzaysal fiksatör kullanılabilir. Ardından tespit için de bu fiksatörler kullanılabilir. Bununla birlikte Dror Paley'nin bu tür durumlar için önerdiği bir tedavi algoritması bulunmaktadır. Bu algoritmaya göre; deformitelerde kemiksel kaynaklı patolojilere, bazen bağsal problemler de eşlik etmektedir. Bu durumda kemiksel kaynaklı deformiteyi düzeltirken, bağsal sıkılaştırma da yapmak gerekir ki, Paley bu osteotomiyi "Opening focal dome osteotomy" kavramıla açıklamıştır (Tablo 2). ${ }^{[11]}$

\section{ÖRNEK UYGULAMALAR}

Şekil 12 ve 13 'te örnek uygulamalar görülmektedir.

\section{KOMPLIKASYONLAR}

Gerek distal femur gerekse proksimal tibia osteotomilerini eksternal fiksatörle uygularken; ameliyat içinde ve sonrasında olmak üzere pek çok komplikasyonla karşılaşma olasılığı bulunmaktadır. ${ }^{[12]}$ Bu komplikasyonların tedavisi bazen hasta ve hekim için oldukça zahmetli olduğundan, komplikasyonlardan sakınmak en önemli basamağı oluşturmaktadır.

Yapılan osteotomilerden iyi fonksiyonel sonuç ve uzun sağkalım elde etmenin en önemli yolu, uygun hasta seçimidir. Lateral kompartman veya patellofemoral kompartmanda artrozu olan bir hastada medial yüksek tibial osteotomi beklenen faydayı sağlamayacaktır. Yine distal femoral varus osteotomisi yapılacak bir hastada, medial eklem aralığı normal olmalıdır. Bunun dışında ameliyat sırasında olası nörovasküler komplikasyon riskini azaltmak için; hasta bacağın uygun şekilde pozisyonlanması, diğer bacak ve ayağın jel pedlerle korunması, osteotomi esnasında nörovasküler yapıların dikkatlice korunması ve osteotominin tam olması olası intraoperatif bazı komplikasyonlardan sakınmayı sağlayacaktır.

$\mathrm{Bu}$ osteotomilerle ilgili görülen komplikasyonlar; nörovasküler hasarlar, yetersiz düzeltme, kaynamama, kaynama gecikmesi, kemik stoğunun azalması, tibial slope (eğim) değişimi, patella infera, kırık, kompartman sendromu, derin ven trombozu, proksimal fragmanın osteonekrozu ve enfeksiyon olarak bildirilmektedir. ${ }^{[12]}$

\section{SONUÇLAR VE GELECEKTE OLASI PROBLEMLER}

Distal femur osteotomileri ve yüksek tibia osteotomileri günümüzde çok yaygın olarak kullanılmasa da, total diz artroplastisi öncesi zaman kazandırıcı yöntemler olarak oldukça önem arz etmektedir. Kaynaklara bakıldığında 10 yıl ve üzerinde sağkalım süresi veren epeyce yayın bulunmaktadır. ${ }^{[13-18]}$

$\mathrm{Bu}$ osteotomilerden erken dönemde beklenen, ağrının giderilmesi ve fonksiyonların iyileşmesidir. Kaynaklara baktığımızda; osteotomi sonrasında VAS (Visual Analog Scale) skorlarında oldukça gerileme ve fonksiyonel sonuçlarda oldukça iyi bir düzelme elde edildiğini görmekteyiz. Yazarlar bu iyileşmeyi; erken dönemde osteotominin hemodinamik etkisine, geç dönemde ise etkilenen eklem aralığında birim kıkırdak yüzeye gelen yüklenmenin azalmasına bağlamaktadır. Bu etkinin uzun dönemde ise, sağkalıma etkisi olduğu kabul edilmektedir. Bu şekilde, pek çok yazar osteotomi sonrası ortalama 10 yıla varan uzun sağkalım sonuçları vermektedir. ${ }^{[13-18]}$

Bununla birlikte, bazı yazarlar özellikle yüksek tibia osteotomisi yapılan hastalarda ortalama beş yıldan sonra sonuçlardaki kötüleşmeyi ve total proteze 

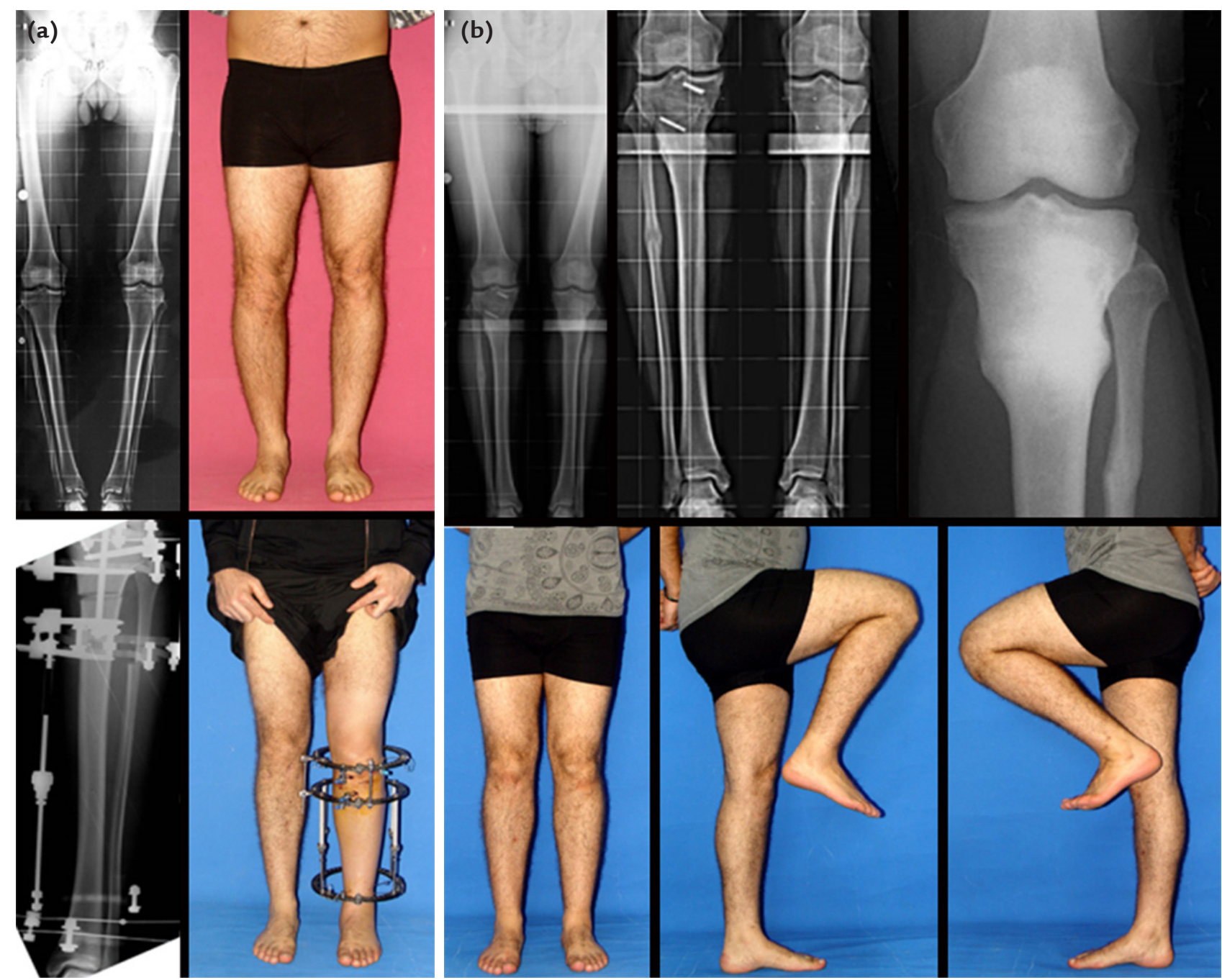

Şekil 12. a, b. Yirmi üç yaşında bilateral genu varum deformitesi olan hastada sol proksimal tibia osteotomisinin tedavi öncesi ve sonrası görüntüleri.

dönmeyi araştırmışlardır. Yapılan bu çalışmalarda; yüksek tibial osteotomi sonrası başarısızlıkta etkili olan faktörler olarak yaşın 50'den büyük olması, kadın hastalar, komorbid (eşlik eden) faktörlerin sayısı, YTO öncesi diz cerrahisi geçirilmesi, bağ laksitesi, patellofemoral ve lateral eklem kıkırdağının hasarlı olması ve yetersiz düzeltme olarak bildirilmektedir.[16,19-21]

Buna karşın diz çevresi osteotomilerindeki uzun dönem başarılı sonuçlarını bildirmekle birlikte, ilerde olası total diz protezi uygulamalarında doğabilecek problemlere dikkat çekmişlerdir. Gaillard ve ark., distal femur varizasyon osteotomisinden ortalama 18,8 yıl sonra total diz protezi yapılan ve ortalama yaşları 66 olan 14 hastayı, primer total diz protezi yapılan 28 hasta ile karşılaştırmış ve hastaların ortalama 3,5 yıllık takip sonuçlarına göre; osteotomi yapılanlarla primer diz artroplastisi yapılan hastalar arasında fonksiyonel sonuçlar açısından fark olmadığını, ancak intraoperatif komplikasyonların osteotomi sonrası total diz protezi yapılan grupta daha fazla olduğunu bildirmişlerdir. ${ }^{[22]}$ Chalmers ve ark. ise; distal femoral osteotomi sonrası total diz artroplastisi yapılan 29 hastanın 31 dizini incelemişler ve bu hastalarda sağkalımı 10 yılda \%88 olarak bulmuşlardır. Ayrıca instabiliteye dikkat çekmişler ve hastaların \%13'ünde varus ve valgus kısıtlayıcı (VVC - Varus-Valgus Constrained) tipte protez kullandıklarını bildirmişlerdir. ${ }^{[23]}$ Benzer sonuçlar yüksek tibial osteotomi sonrası yapılan total diz artroplasti serilerinde de görülmüştür. Hernigou ve ark., yüksek tibial osteotomi ile total diz artroplastisi arasındaki sürenin ortalama 14 yıl olduğu 98 hastalık çalışmalarının sonuçlarına göre, ortalama 17 yıllık takipte 10 yıllık 


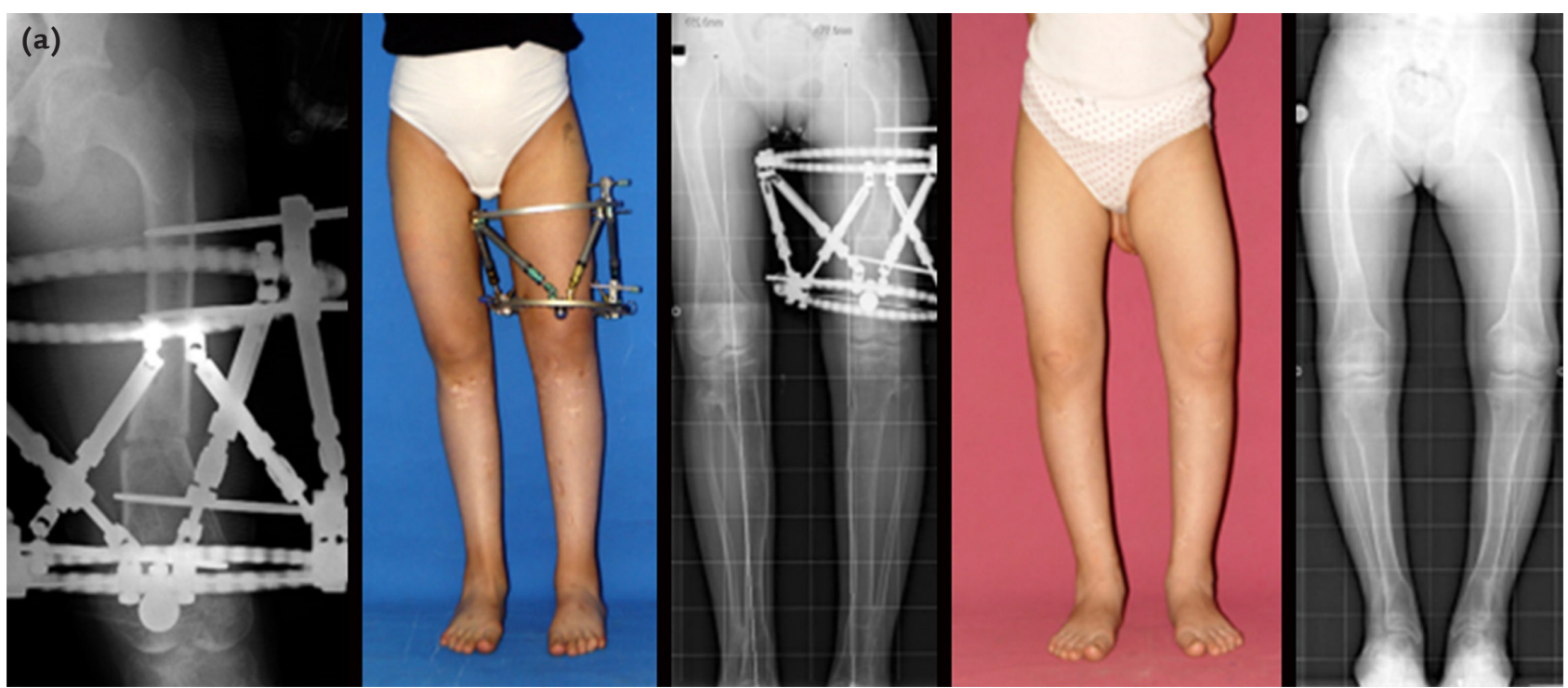

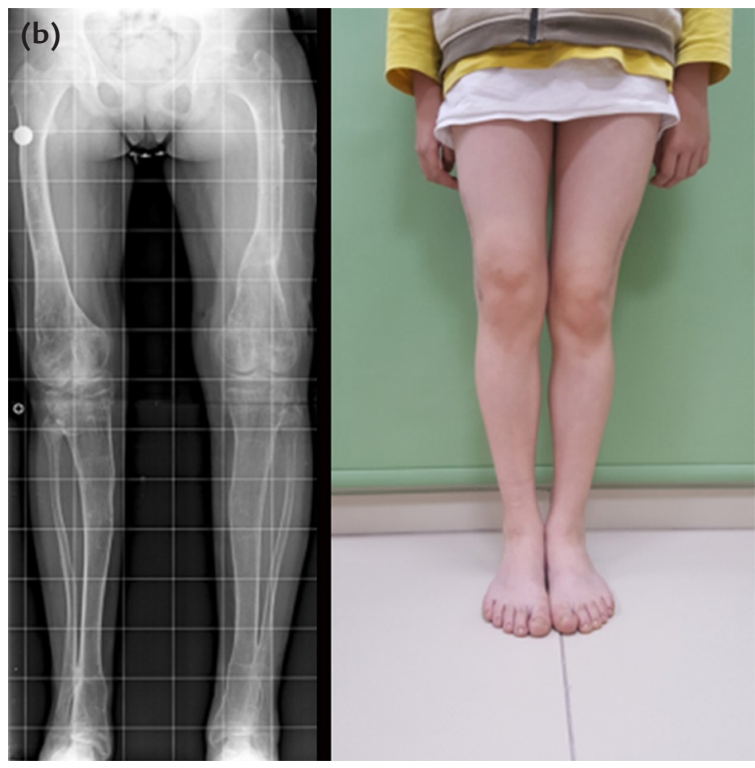

sağkalımın \%95 olduğunu bildirmişlerdir. ${ }^{[24]}$ Chalmers ve ark. ise, yüksek tibial osteotomi ile total diz artroplastisi arasındaki sürenin ortalama 13 yıl olduğu 207 hastanın 231 dizini ortalama sekiz yıl takip etmişler ve 10 yıllık sağkalımı \%97 olarak bildirmişlerdir. ${ }^{[25]}$ Her iki çalışmada da, osteotomi sonrası total diz artroplastisinin güvenle yapılabileceği ve komplikasyon oranının $\% 5$ düzeyinde olduğu ifade edilmiştir.

\section{SONUÇ}

a. Deformite, normal anatomiden sapma olarak tanımlanmaktadır. Bu sapma, uzunluk, rotasyon, angulasyon veya translasyon şeklinde olabilir.
Şekil 13. a, b. Hipofosfatemik raşitizm tanısıyla takip edilen ve femurda deformitenin nüks etmesi sebebiyle sol femurdan düzeltici osteotomi ve bilgisayar destekli uzaysal fiksatörle tedavi sonrası görüntüsü. b. Bir ekstremitede deformite olup olmadığını anlamak için önce dizilim eksenini ve yönelim açılarını çizmek gerekir. Daha sonra bu ekstremitedeki deformitenin hangi kemikten kaynaklandığını anatomik veya mekanik eksenleri ve yönelim açılarını kullanarak ortaya koymak ikinci adımı oluşturmaktadır. Deformitenin hangi kemikten kaynaklandığını bulduktan sonraki üçüncü adım ise; deformitenin merkezini saptamak ve osteotomiyi yaparak, bu ekstremitede var olan tüm patolojileri giderecek şekilde bir cihaz kullanmak gerekir.

c. Doğru bir deformite analizi yapmak, bu yöntemi kullanırken en önemli aşamayı oluşturmaktadır. Deformite analizi ve tedavi planlaması doğru yapılmışsa, son adımda cerrah hangi osteosentez materyalini kullanmakta tecrübeliyse, o implantı kullanmalıdır. Plak-vida, intramedüller çivi, sirküler fiksatör, monolateral fiksatör ve bilgisayar destekli fiksatörler günümüzde en çok tercih edilen osteosentez yöntemleridir.

d. Bizim bu cerrahi uygulamalara başlamak isteyen genç meslekdaşlarımıza önerimiz; doğru bir deformite analizi yaparak iyi bir tedavi öncesi planlama yapmak, ardından sirküler fiksatörlerde olduğu gibi tedrici düzeltme yapan sistemleri kullanmak, sonra tecrübe arttıkça daha güncel uygulamalara yönelmek olmalıdır. 
e. Gerek distal femoral osteotomiler gerekse yüksek tibial osteotomiler sonrası; erken dönemde hastanın ağrısı geçmekte ve fonksiyonel geri kazanım tatmin edici olmaktadır. Etkilenen eklem kompartmanındaki birim kıkırdak yüzeye gelen yüklenmenin azalması sonucunda ise; uzun dönemde sağkalıma olumlu etki etmekte ve 10 yıla varan sürede total diz protezine dönüş geciktirilebilmektedir.

f. Diz çevresi osteotomileri sonrası başarısızlık sebepleri arasında uygun olmayan hasta seçimi, yaşın 50'den fazla olması, kadın hasta, komorbid faktörlerin (DM, KOAH, kalp yetmezliği, diyaliz vb.) fazlalığı, bağ laksitesi, yetersiz düzeltme, osteotomi öncesi diz cerrahisi geçirilmesi ve patellofemoral eklem ile diğer eklem aralığının hasarlı olması olarak verilmektedir.

g. Ancak diz çevresi osteotomileri sonrası uzun dönem sonuçlara bakıldığında; intraoperatif komplikasyonlardan sakınıldığı takdirde, uzun dönem sonuçların primer total diz artroplastisi yapılan vakalarla benzer olduğu ve güvenle uygulanabileceği bildirilmektedir.

\section{Teşekkür}

Dr. Melih Civan'a şekil çizimleri için çok teşekkür ederim.

\section{KAYNAKLAR}

1. Chao EY, Neluheni EV, Hsu RW, Paley D. Biomechanics of malalignment. Orthop Clin North Am 1994;25(3):379-86.

2. Cooke TD, Li J, Scudamore RA. Radiographic assessment of bony contributions to knee deformity. Orthop Clin North Am 1994;25(3):387-93.

3. Moreland JR, Bassett LW, Hanker GJ. Radiographic analysis of the axial alignment of the lower extremity. J Bone Joint Surg Am 1987;69(5):745-9. Crossref

4. Paley D, Tetsworth K. Mechanical axis deviation of the lower limbs. Preoperative planning of uniapical angular deformities of the tibia or femur. Clin Orthop Relat Res 1992;(280):4864. Crossref

5. Green WT, Wyatt GM, Anderson M. Orthoroentgenography as a method of measuring the bones of the lower extremities. J Bone Joint Surg Am 1946;28:60-5.

6. Paley D, Herzenberg JE. Chap. 4: Frontal plane mechanical and anatomic axis planning, In: Principles of Deformity Correction. Berlin: Springer; 2002. pp.60-5.

7. Cakmak M, Civan M. Ankle Deformities. In: Çakmak M, Şen C, Eralp L, Balci H, Civan M, editors. Basic Techniques for Extremity Reconstruction. Swiss: Springer; 2018. pp.413-39.

8. Sen C, Polat G. Anatomic and mechanical planning and finding the CORA. In: Çakmak M, Şen C, Eralp L, Balci $\mathrm{H}$, Civan M, editors. Basic Techniques for Extremity Reconstruction. Swiss: Springer; 2018. pp.295-307.

9. Paley D, Herzenberg JE, Tetsworth K, McKie J, Bhave A. Deformity planning for frontal and sagittal plane corrective osteotomies. Orthop Clin North Am 1994;25(3):425-65.
10. Uysal M. Osteotomy Rules and Types. In: Çakmak M, Şen C, Eralp L, Balci H, Civan M, editors. Basic Techniques for Extremity Reconstruction. Swiss: Springer; 2018. pp.425-65.

11. Paley D, BhatnagarJ, Herzenberg JR, Bhave A. New procedures for tightening knee collateral ligaments in conjunction with knee realignment osteotomy. Orthop Clin North Am 1994;25(3):533-55.

12. Koyonos L, Slenker N, Cohen S. Complications in brief. Clin Orthop Relat Res 2012;470(12):3630-6. Crossref

13. Ekeleand A, Nerhus TK, Dihmen S, Heir S. Good functional results of distal femoral open-wedge osteotomy of knees with lateral osteoarthritis. Knee Surg Sports Traumatol Arthrosc 2016;24(5):1702-9. Crossref

14. Ekeland A, Nerhus TK, Dihmen S, Thornes E, Heir S. Good functional results following high tibial opening wedge osteotomy of knees with medial osteoarthritis. A prospective study with a mean of 8,3 years of follow up. Knee 2017;24(2):380-9. Crossref

15. Polat G, Balci HI, Cakmak MF, Demirel M, Sen C, Asik M. Longterm results and comparison of the three different high tibial osteotomy and fixation techniques in medial compartment arthrosis. J Orthop Surg Res 2017;12(1):44-51. Crossref

16. El-Galaly A, Nielsen PT, Jensen SL, Kappel A. Prior high tibial osteotomy does not affect the survival of total knee arthroplasty results from Danish Knee Arthroplasty Registry. J Arthroplasty 2018;33(7):2131-5.e1. Crossref

17. Hantes ME, Natsoridis P, Koutalos AA, Ono Y, Doxariotis $\mathrm{N}$, Malizos KN. Satisfactory functional and radiological outcomes can be expected in young patients under 45 years old after open-wedge high tibial osteotomy in a longterm follow-up. Knee Surg Sports Traumatol Arthrosc 2018;26(11):3199-205. Crossref

18. Kuwashima U, Okosaki K, Iwasaki K, Akasaki Y, Kawamura $\mathrm{H}$, Mizu-Uchi H, Hamai S, Nakashima Y. Patient reported outcomes after high tibial osteotomy show comparable results at different ages in the mid-term to long-term followup. J Orthop Sci 2019;24(5):855-60. Crossref

19. Khosbin A, Sheth $U$, Ogilvie-Harris D, Mahomed N, Jenkinson R, Gandhi R, Wasserstein D. The effect of patient, provider, and surgical factors on survivorship of high tibial osteotomy to total knee arthroplasty: a population -based study. Knee Surg Sports Traumatol Arthrosc 2017;25(3):887-94. Crossref

20. van Wulfften Palthe AFY, Clement ND, Temmerman OPP, Burger BJ. Survival and functional outcome of high tibial osteotomy for medial knee osteoarthritis: a 10-20 year cohort study. Eur J Orthop Traumatol 2018;28(7):1381-9. Crossref

21. Keenan DJF, Clement ND, Nutton JR, Keating JA. Older age and female gender are independant predictors of early conversion to total knee arthroplasty after high tibial osteotomy. Knee 2019;26(1):207-12. Crossref

22. Gaillard R, Lording T, Lustig S, Servien E, Neyret P. Total knee arthroplasty after varus distal femoral osteotomy vs native knee: similar results in a case control study. Knee Surg Sports Traumatol Arthrosc 2017;25(11):3522-9. Crossref

23. Chalmers BP, Limberg AK, Athey AG, Perry KI, Pagnano MW, Abdel MP. Total knee arthroplasty after distal femoral osteotomy, long-term survivorship and clinical outcomes. Bone Joint J 2019;101-B(6):660-6. Crossref

24. Hernigou P, Huys M, Pariat J, Roubineau F, Lachaniette CHF, and Dubory A. Comparison of fixed-bearing and mobile bearing total knee arthroplasty after high tibial osteotomy. Int Orthop 2018;42(2):317-22. Crossref

25. Chalmers BP, Limberg AK, Tibbo ME, Perry KL, Pagnano MW, Abdel MP. Total knee arthroplasty after high tibial osteotomy results in excellent long-term survivorship and clinical outcomes. J Bone Joint Surg Am 2019;101(11):9708. Crossref 